\title{
METZ'S CASE AGAINST SUPERNATURALISM
}

\section{ERIK J. WIELENBERG}

\author{
DePauw University
}

I take it that the central project of Metz's book is to explicate his theory of meaning in life - the fundamentality theory - and to make the case that, when it comes to theories about what makes human lives meaningful, 'the fundamentality theory is now the one to beat' (p. 249). One important rival to Metz's fundamentality theory is supernaturalism, the view that meaning in life is constituted by a relationship with a spiritual realm, where a spiritual realm is a realm of 'persons [...] who are beyond (our) space and time and composed of something other than sub-atomic particles' (p. 79). Thus, the existence of God (as traditionally understood in the most prominent version of monotheism) or non-physical souls entails the reality of a spiritual realm. In making the case that the fundamentality theory is the theory to beat, Metz devotes considerable critical attention to supernaturalism. In these remarks I examine Metz's arguments against supernaturalism and make the case that they are, for the most part, unsuccessful. However, it seems to me that Metz's book does contain the materials for a compelling objection to supernaturalism. After criticizing the arguments against supernaturalism that Metz actually gives, I outline a more compelling argument that I think he should have given.

Metz takes the dominant version of supernaturalism to be purpose theory, according to which meaning in life is constituted by doing what God intends one to do with one's life (pp. 78-9). He also takes it that the strongest argument in favour of purpose theory is 'that God's purpose could be the sole source of invariant ethical rules, where our lives would obtain meaning by conforming to them, and would be meaningless if such rules did not even exist' (pp. 84-5). I will call that argument the argument for purpose theory. A crucial premise of this argument is the claim that the existence of morally wrong actions entails the existence of God. 
Metz attacks the purpose theory in two main ways. First, he objects to the argument for purpose theory, suggesting that if this argument fails then 'one of the most influential and powerful reasons for believing in purpose theory should be disbelieved' (p. 97). Second, he advances an objection to purpose theory itself. I have doubts about the success of Metz's objection to the argument for purpose theory as well as about his objection to purpose theory itself.

At the heart of Metz's objection to the argument for purpose theory is the contention that anyone who makes all of the following claims is endorsing a set of claims that is 'inconsistent' or 'incoherent' (p. 88):

(i) I know that some actions are morally wrong.

(ii) I know that the existence of some morally wrong actions entails the existence of God.

(iii) It's not the case that I know that God exists.

According to Metz, each of us should accept (i) and (iii) and therefore should reject (ii). But if we reject (ii), then we are rejecting the claim to know a crucial premise of the argument for purpose theory, in which case that argument cannot give us knowledge of its conclusion. To support the claim that we should accept (i) and (iii), Metz follows John Cottingham in holding that whereas we have conclusive evidence for the truth of (i), the available evidence for the existence of God - i.e. evidence from the observable world and religious experience - is at best ambiguous. As Metz puts it, '[i]n light of the conclusive evidence that wrongness exists and the inconclusive evidence that God does' (p. 91), we should accept (i) and (iii). Consequently, ' $\mathrm{t}$ ] o be coherent, one should hold that wrongness is a function of something other than God, since [...] one is not likely to find either more evidence that God exists or less evidence that wrongness does' (p. 91). The foundation of Metz's argument here is his contention that we have differing amounts of evidence for the existence of morally wrong acts on the one hand and the existence of God on the other.

I think that this argument fails. To see why, first note that the following three claims do not constitute an inconsistent triad:

(iv) S knows that some actions are morally wrong.

(v) S knows that the existence of some morally wrong actions entails the existence of God.

(vi) It's not the case that $\mathrm{S}$ knows that God exists. 
Consider a subject $S$ who accepts and has conclusive evidence for the existence of morally wrong acts and also accepts and has conclusive evidence for the claim that the existence of morally wrong acts entails the existence of God but simply never reflects on these two claims together. Because $S$ fails to put two and two together, $S$ lacks the knowledge that God exists despite the fact that the existence of God is entailed by the conjunction of two things that $S$ knows. Suppose, then, that at a certain point $S$ comes to reflect on the two claims together. On the basis of such reflection, $S$ is in a position to infer - and hence come to know - that God exists. And $\mathrm{S}$ can attain this knowledge even without conclusive evidence for God's existence derived from the observable world or religious experience. Thus, someone who initially knows that some acts are wrong but doesn't know that God exists might come to know that the existence of morally wrong acts entails the existence of God and on that basis (rather than on the basis of evidence derived from the observable world or religious experience) come to know that God exists. Consequently, Metz's position that we should accept (i) and (iii) and reject (ii) appears to be inadequately supported; for all that Metz has said, it is at least as plausible that we should accept (i) and (ii) and reject (iii).

Of course, even if Metz's critique of the argument for purpose theory fails, if Metz's critique of purpose theory itself succeeds then the theory should be rejected in any case. So, let us consider Metz's criticism of purpose theory itself. That criticism has two premises, summarized by Metz thusly: 'Premise 1 contends that the best explanation of a Godcentred theory includes the claim that God has certain properties such as simplicity, immutability, atemporality, or perhaps infinitude' and 'Premise 2 maintains that these properties are incompatible with a purposive God' (p. 108). It seems to me that Metz's strategy here is best construed as making the case that purpose theory cannot be true because it entails a contradiction:

\section{Metz's Incompatibility Argument}

(1) If purpose theory is true, then (a) God is simple, immutable, atemporal, and infinite and (b) God is purposive.

(2) But if God is simple, immutable, atemporal, and infinite, then it's not the case that God is purposive.

(3) So, if purpose theory is true, then God is purposive and it's not the case that God is purposive.

(4) Therefore, purpose theory is false. 
Metz supports premise (1) of this argument by making the case that the most plausible strategy for supporting the purpose theorist's contention that only God could imbue human lives with meaning is to argue that God is uniquely capable of filling this role in virtue of divine properties that are 'utterly supernatural' and 'that nature simply could not exhibit' (p. 110). Metz suggests that the most likely candidates for such properties are simplicity, immutability, atemporality, and infinity (pp. 110-2). And, of course, it is part of purpose theory that God is purposive (i.e. has purposes) since, according to the theory, our lives are meaningful just to the extent that we fulfil God's purposes for our lives.

In support of premise (2), Metz points out that there is at least the appearance of incompatibility between each of the 'qualitative' properties of simplicity, immutability, atemporality, and eternality on the one hand purposiveness on the other. For example, Metz claims that 'to the extent that we can conceive of an immutable being beyond time, such a being appears to be unable to engage in goal-directed activity' (pp. 112-3).

Worries about tension between the divine attributes highlighted by Metz and divine personhood and agency have a long history; as Metz indicates, a number of thinkers sympathetic to traditional western monotheism have attempted to show that such tension is merely apparent by explaining how one or more of the qualitative divine attributes Metz identifies is compatible with divine agency (p. 115, n. 14). However, Metz does not engage with any of that work, and it seems to me that that limits the force of his criticism here. Of course, it may be that proper engagement with such work would constitute a book of its own, so perhaps Metz cannot be faulted too much for omitting such a project in the present book. Still, I think that his lack of engagement with such work leaves at least one important objection to his argument that he does consider without an adequate response.

The objection I have in mind is an objection to the first premise of Metz's incompatibility argument raised by Philip Quinn. Quinn suggests that God could serve as the source of meaning in our lives not in virtue of His possession of simplicity, immutability, atemporality, and infinity but rather in virtue of His being the creator of the universe (p. 114). This is a property that nature itself obviously could not possess. Metz replies to this objection as follows: '[S]ince the universe is essentially spatiotemporal, God must be an atemporal being to have been its creator [...] How could a person who is beyond time create a spatio-temporal world, when doing so would appear to require time?' (p. 115) I take it that Metz 
has in mind the following line of reasoning: If God is the creator of the universe, then God is atemporal (because if He were temporal, He would exist within the spatio-temporal universe and hence could not be its creator); however, if God is atemporal, then He cannot be the creator of the universe (because the act of creating the spatio-temporal world would itself have to take place in time). Therefore, God could not be the creator of the spatio-temporal universe.

Notice that if this argument works, it does much more than answer Quinn's reply to Metz's critique of purpose theory; it identifies an incompatibility at the heart of the traditional monotheism, since the God of traditional monotheism is typically understood to have created the spatio-temporal universe out of nothing. It is therefore unsurprising that a number of theistic philosophers have tried to explain how an atemporal God could indeed create the spatio-temporal universe; some prominent contemporary examples include Eleonore Stump and Norman Kretzmann (1981, particularly pp. 448-50) and William Lane Craig $(1978,1998) .{ }^{1}$ Because Metz does not engage with any of the existent efforts to explain creation of the spatio-temporal universe by an atemporal God, his reply to Quinn's critique of the incompatibility argument is unconvincing.

As I noted above, purpose theory is just one version of supernaturalism. Metz aims to refute not just purpose theory but the broader view supernaturalism as well. His case against supernaturalism itself depends on two main arguments. ${ }^{2}$ The first argument is simply that supernaturalism mistakenly implies of many actual lives that they are meaningless if there is no spiritual realm; call this the argument from cases. Metz invites the reader to consider the lives of 'Einstein, Darwin, Dostoevsky, Picasso, Mandela, and Mother Teresa', suggesting that many people 'would find these lives to be meaningful in the absence of anything perfect or supernatural' (p. 144). I think this argument has some force, though I think it could be strengthened in a way I explain below.

${ }^{1}$ An important difference between the view of Stump and Kretzmann on the one hand and Craig on the other is that Craig holds that God is atemporal prior to creating the spatio-temporal universe but becomes temporal upon creating such a universe whereas Stump and Kretzmann do not hold such a view. However, that issue is not relevant to the present discussion.

${ }^{2}$ Metz advances three arguments in his critical discussion of supernaturalism, but as he points out the first of these tells at most against one particular type of supernaturalism 'soul-centred theory' - but not against supernaturalism in its entirety (142-3). 
Metz's second argument against supernaturalism parallels his critique of the argument for purpose theory discussed above. He claims that anyone accepting all of the following three claims is guilty of inconsistency or incoherence:

(i+) I know that the existence of meaning entails the existence of a spiritual realm.

(ii+) I know that meaning exists.

(iii+) It's not the case that I know that a spiritual realm exists.

According to Metz, the only reasonable way to avoid incoherence is to reject (i+), which means rejecting supernaturalism (p. 145). However, it seems to me that this argument fails for much the same reason that Metz's earlier critique of the argument for purpose theory fails. It seems open to the supernaturalist to hold that it is (iii+) that should be rejected because her knowledge of supernaturalism and her knowledge of the existence of meaning enable her to know that a spiritual realm exists.

Supernaturalism receives further attention in the final chapter of Meaning in Life, this time in the context of the threat of nihilism. When combined with the denial of the existence of a spiritual realm, supernaturalism yields the result that all lives are meaningless (nihilism). In short: supernaturalism + atheism $=$ nihilism. Metz wants to refute such a foundation for nihilism but believes that his two arguments against supernaturalism (discussed above) will not work against a supernaturalist who is also an atheist (p. 242). Accordingly, in the final chapter of the book Metz defends a new argument aimed at showing that 'there is little or no reason to adopt supernaturalism, if atheism is true' (p. 243).

Metz's argument for that claim appeals to evolutionary considerations. The idea seems to be that in a purely natural universe devoid of a spiritual realm our 'central characteristics' - including various dispositions to make certain sorts of value judgments - are entirely products of evolutionary processes. And if such dispositions are products of evolutionary processes, we are not disposed to make value judgments that are informed by or appeal to the spiritual realm because ' $\mathrm{t}$ ] he kinds of value judgments that would have enabled purely physical creatures to be naturally selected are ones appealing to imperfect standards that could be fulfilled on earth' (p. 244). And if that is the case, then, according to Metz, supernaturalism is undermined and hence the argument from supernaturalism + atheism to nihilism fails because 'one premise provides good reason to reject the other' (p. 244). 
One problem with this argument is that it appears to depend on the assumption that if a spiritual realm did not exist then our evolutionary ancestors would have recognized that fact: 'Early members of Homo sapiens would not have judged their own or others' behaviour in light of standards that, ex hypothesis, could never be fulfilled' (p. 244). But of course our ancestors might have judged behaviour in light of unfulfillable standards if they had mistakenly believed that such standards could be fulfilled, and Metz provides no reason to rule out that possibility.

However, the most serious problem with the argument is that it at most supports a conclusion about what sorts of value judgments we would in fact make if atheism were true but does not appear to support any particular conclusion about which value judgments we are justified in making if atheism is true. Metz's reasoning yields at most the conclusion that atheism implies that humans will in fact not accept supernaturalism, but the conclusion he is aiming for is that we lack justification for accepting supernaturalism. It appears perfectly reasonable for a supernaturalist nihilist to hold that Metz has provided a plausible evolutionary explanation of why human beings fail to recognize the truth of supernaturalism but that he has not provided any good reason to reject either the claim that supernaturalism is true or the claim that we would be justified in believing supernaturalism to be true. So, as far as I can see, the intended conclusion does not follow from the premises Metz provides.

It seems to me, then, that most of Metz's arguments against supernaturalism and against what he takes to be the strongest form of supernaturalism - purpose theory - have significant weaknesses. The one exception is what I have called the argument from cases. That argument rests on the claim that certain lives (e.g. the lives of Darwin, Einstein, and Mother Teresa) are meaningful even if there is no spiritual realm. I said above that this argument could be strengthened. To see how, consider that a supernaturalist might object to this sort of argument by claiming that without a plausible explanation of how the lives of Darwin et al. could be meaningful in the absence of a spiritual realm, the objection is not compelling. While I am not terribly sympathetic to this supernaturalist critique myself, I think it is worth considering, if only because it points toward a way that Metz could strengthen the argument from cases. He could accomplish this by appealing to his own fundamentality theory, the core idea of which is that a human person's life is meaningful to the extent that the person living it 'employs her reason and in ways that 
positively orient rationality towards fundamental conditions of human existence' (p. 222). As Metz points out, the fundamentality theory can account for both (a) the meaningfulness of the lives of Einstein et al. even in the absence of a spiritual realm and (b) 'the relevance of supernatural conditions for meaning in life' (p. 232). Metz explains how his fundamentality theory accounts for (b) as follows: 'If God existed, it would be incredibly important to know about Him and to make works of art about Him, as He would be largely responsible for nearly everything that goes on in the physical and spiritual worlds and in the human experience' (p. 232). On theism, God is the fundamental condition of human life, so the fundamentality theory implies that if theism is true, then God is extremely relevant to whatever meaning human lives might have. In light of this, Metz can plausibly claim that fundamentality theory has an explanatory edge over supernaturalism in that it accounts for both (a) and (b) whereas supernaturalism founders when it comes to explaining (a). It seems to me that this is the most compelling argument against supernaturalism suggested by Metz's book.

\section{BIBLIOGRAPHY}

Craig, William Lane. 1978. 'God, Time, and Eternity', Religious Studies 14 (4): 497-503

Craig, William Lane. 1998. 'The Tensed vs. Tenseless Theory of Time: A Watershed for the Conception of Divine Eternity', in Robin Le Poidevin (ed.), Questions of Time and Tense (Oxford: Clarendon Press), pp. 221-50

Stump, Elenore, and Kretzmann, Norman. 1981. 'Eternity', The Journal of Philosophy, 78 (8): 429-58 